\title{
Progressive Supranuclear Palsy
}

\author{
Lawrence I. Golbe, MD ${ }^{1}$ \\ ${ }^{1}$ Department of Neurology, Rutgers Robert Wood Johnson Medical \\ School, New Brunswick, New Jersey \\ Semin Neurol 2014;34:151-159.
}

\begin{abstract}
Address for correspondence Lawrence I. Golbe, MD, Department of Neurology, Rutgers Robert Wood Johnson Medical School, 125 Paterson Street, Suite 6200, New Brunswick, NJ

(e-mail: golbe@rutgers.edu).
\end{abstract}

\begin{abstract}
Keywords

- progressive supranuclear palsy

- brainstem

- tau

- parkinsonism

- frontal dementia

Progressive supranuclear palsy is a disorder of tau protein aggregation. Its clinical spectrum is now known to be wider than originally described, with a phenotype resembling Parkinson disease accounting for a third of cases. However, at least half of the patients with PSP exhibit the classic bradykinesia with disproportionate postural instability, erect posture with nuchal rigidity, frontal behavioral and cognitive changes, vertical gaze palsy, and other disabling brainstem deficits. Nonmendelian genetic risk factors exist, but PSP is almost entirely sporadic, with a prevalence of five to six persons per 100,000 , mean onset age of 63 , and median survival of 7 years. Clinical diagnostic criteria with excellent specificity and a clinical rating scale sensitive to progression are available. Diagnosis remains clinical, although magnetic resonance imaging and cerebrospinal fluid measures are showing promise as early-stage screening tools. Multiple candidate neuroprotective medications have proven ineffective to date. Treatment remains supportive, although coenzyme Q-10 has shown preliminary symptomatic efficacy and levodopa may provide transient, modest benefit.
\end{abstract}

Fifty years have passed since the seminal clinical-pathological description of progressive supranuclear palsy (PSP) by Steele, Richardson, and Olszewski. ${ }^{1}$ Before that time, without modern imaging or an opportunity to observe a levodopa response, PSP was typically misdiagnosed as vascular parkinsonism or Parkinson disease (PD). The autopsy picture was typically misdiagnosed as postencephalitic parkinsonism or as a form of Alzheimer disease.

The most important scientific discoveries in PSP over the past half-century are probably that tau protein undergoes certain posttranslational abnormalities and forms the disorder's characteristic neurofibrillary tangles ${ }^{2}$; that an inversion of a segment of chromosome 17 including the tau gene is overrepresented in affected individuals ${ }^{3}$; that a mitochondrial energy failure is part of $\mathrm{PSP}^{4}$; and that the pathologic picture described by Steele et al can produce a variety of clinical phenotypes. ${ }^{5}$ Among the most useful clinical and research tools have been several animal tauopathy models using mutant human tau knock-ins, ${ }^{6}$ the development of clinical diagnostic criteria with high specificity and positive predictive value, ${ }^{7}$ and a PSP-specific clinical disability rating scale that is sensitive to disease progression over a short period. $^{8}$
But PSP lags most other neurological disorders on the treatment front. The loss of postsynaptic striatal neurons in $\mathrm{PSP}^{9}$ may explain its poor response to dopamine replacement or dopamine receptor stimulation. Another factor is PSP's nonspecific presentation with postural instability or behavioral changes and the absence of a practical, early diagnostic test. These conspire to delay the correct diagnosis by 3 or 4 years, by which time half of the clinical course has passed and neuroprotective treatment is unlikely to help. For this reason, it will be critical to develop a diagnostic marker that can inexpensively identify the disease in its earliest stages.

Nevertheless, perhaps the most active area of research in PSP is neuroprotective treatment. Motivating the search is the insight that any agent preventing aggregated tau protein from causing damage in PSP could do the same in Alzheimer's disease, with major public health implications.

\section{Disease Frequency}

The population prevalence ratio for living cases of PSP in fullyascertained, community-based series approximates 5-6 cases per $100,000 .^{10-13}$ Of these, only 1.5 per 100,000 are already accurately diagnosed. ${ }^{10-12}$ This means that for each
Issue Theme Atypical Parkinsonian Disorders; Guest Editors, Yvette Bordelon, MD, PhD, and Carlos PorteraCailliau, MD, PhD
Copyright @ 2014 by Thieme Medical Publishers, Inc., 333 Seventh Avenue, New York, NY 10001, USA. Tel: +1(212) 584-4662.
DOI http://dx.doi.org/ 10.1055/s-0034-1381736. ISSN $0271-8235$. 
person carrying an accurate diagnosis of PSP, three have been diagnosed inaccurately or not at all. By comparison, the prevalence of PD is typically measured at 150 to 200 per 100,000 . The incidence ratio, calculated indirectly from the prevalence and the disease duration, is 1 to 2 per 100,000 per year. No geographical, ethnic, or racial disparities in PSP frequency have been found, but only one study outside of northern-European-derived populations has been performed. ${ }^{13}$

\section{Exogenous Risk Factors and Comorbidities}

There have been few wide-ranging controlled studies of exogenous risk factors in PSP. ${ }^{14-16}$ The only risk confirmed by multiple studies is lesser educational attainment. Explanatory speculation points to lesser "synaptic reserve" or to greater occupational or residential exposure related to industrial work or lower income. Rural living, pesticide exposure, well-water use, and nonsmoking, all of which are associated with PD in many studies, appear unrelated to PSP. Only one study of dietary factors in PSP has appeared, with no positive finding except that study patients consumed slightly more meat and less fruit than controls. ${ }^{16}$ The significance of this finding is unclear.

The abnormal lipid peroxidation in affected brain areas in PSP $^{17}$ suggests that toxins or foods promoting that abnormality should be a focus of future case-control surveys. Such surveys should also carefully scrutinize factors related to lesser education such as rural living, industrial employment, and proximity to toxins.

Male gender approximates 55\% in most series, but this could result from referral bias at academic centers or brain banks. ${ }^{5}$ Community-based series to date have had insufficient statistical power to calculate a valid gender ratio for PSP.

The reduced risk for most types of cancer in PD appears not to apply to PSP. ${ }^{18}$ The same applies to the low risk of stroke and hypertension in PD. This may be explained by the absence in PSP of the dysautonomic relative hypotension that is common in PD. In fact, one study found hypertension to be overrepresented in PSP. ${ }^{19}$

\section{Genetic Risk Factors}

To date, by far the most important genetic risk factor is the $\mathrm{H} 1$ haplotype of the MAPT gene, which encodes tau protein. This variant, discovered in $1999,{ }^{3}$ is actually an inversion of a segment of chromosome 17 with several superimposed deletions and partial reinversions. The resulting abnormalities are discussed elsewhere in this issue. Associations of singlenucleotide genetic markers were reported in $2011^{20}$ to occur in a handful of other genes. One of these, EIF2AK3, the gene for protein kinase R-like endoplasmic reticulum kinase (PERK) regulates protein transcription. Another, syntaxin-6 (STX6), helps in vesicular exocytosis. A third, myelin oligodendrocyte basic protein (MOBP), is a component of myelin. The roles of these proteins in the pathogenesis of PSP remain unclear. The same 2011 single-nucleotide-polymorphism-based study found a PSP association for a locus in the MAPT gene independent of the $\mathrm{H} 1$ haplotype. It may help control levels of tau expression.

A whole-exome sequencing project for PSP is nearing completion and is expected to report results in late 2014.

\section{Pathophysiology}

Progressive supranuclear palsy is remarkable for the anatomical and neurochemical variety of central nervous system (CNS) areas affected. Damage to the dopaminergic nigrostriatal pathway and cholinergic damage in many areas are the most consistent, severe neurotransmitter-related changes in PSP. $^{21}$ The latter involve cerebral cortex, particularly in primary motor and premotor areas. ${ }^{22}$ Contributing to the pathogenesis of motor parkinsonism in PSP is moderate damage to the GABAergic function of striatum, globus pallidus interna, and globus pallidus externa. ${ }^{23}$ Serotonergic receptor sites are reduced in the cortex, but unlike in $\mathrm{PD}$, are normal in basal ganglia. There is diffuse loss of adrenoceptors resulting from severe damage to the locus ceruleus. ${ }^{24}$ Peptidergic systems and the mesolimbic and mesocortical dopaminergic systems are intact, unlike in PD.

Although damage to basal ganglia and cerebral cortex are important in PSP, loss of brainstem structures is the disease's "signature." The pedunculopontine nucleus (PPN), which includes cholinergic, GABAergic, and glutamatergic areas, is affected in PSP, as it is in PD. ${ }^{25}$ This may account for the postural instability in the disorders and has made deep-brain stimulation of the PPN an object of recent therapeutic research.

Another brainstem area importantly affected in PSP is the dorsal midbrain, where vertical gaze is controlled. The substantia nigra pars reticulata, which projects to the superior colliculus, degenerates in PSP, but is only mildly affected in PD. This may be an important factor in the vertical gaze palsy characteristic of PSP. Atrophy of the dorsal midbrain is disproportionate to that of other brainstem structures in PSP and is a specific if insufficiently sensitive diagnostic feature on magnetic resonance imaging (MRI).

Many other brainstem areas are affected in PSP, including the motor nuclei of the cranial nerves in the advanced stages of the disease. In recent years, damage to subcortical white matter tracts, ${ }^{26}$ the cerebellar dentate, ${ }^{27}$ and the thalamus ${ }^{28}$ have been well characterized. Even the spinal cord is not spared, with damage to the nucleus of Onuf explaining the urinary bladder dysfunction of PSP.

\section{Diagnostic Studies}

Many diagnostic tests have been investigated at least in a single study and have been found useful in distinguishing PSP from some of its diagnostic competitors. However, none has proven effective in prospectively distinguishing early, stillundiagnosable atypical parkinsonian conditions using eventual clinical outcome or autopsy as the "gold standard." These include transcranial sonography of the substantia nigra and basal ganglia, ${ }^{29}$ positron emission tomographic (PET) imaging of glucose utilization, ${ }^{30}$ presynaptic dopamine uptake ${ }^{31}$ or postsynaptic dopamine receptors, ${ }^{32}$ single photon 
emission computed tomographic (SPECT) imaging of tissue metabolism/perfusion, ${ }^{33}$ SPECT imaging of the presynaptic dopamine transporter, ${ }^{34}$ magnetic resonance spectrography of basal ganglia, ${ }^{35}$ diffusion tensor imaging of white matter tracts, ${ }^{26}$ optical coherence tomography of the retina, ${ }^{36}$ electrophysiological assessment of brainstem reflexes, ${ }^{37}$ and cerebrospinal fluid (CSF) measures of phosphorylated tau and neurofilament light chain. ${ }^{38}$

In routine clinical practice, establishing a diagnosis of PSP relies only on the history, neurologic exam, and MRI. The most important diagnostic alternative is "vascular PSP," which can mimic many features of degenerative PSP. ${ }^{39}$ Magnetic resonance imaging would also reveal or direct suspicion toward other multifocal anatomical lesions of the basal ganglia, normal-pressure hydrocephalus, and Creutzfeldt-Jakob disease, all of which can mimic PSP. Magnetic resonance imaging findings in PSP are discussed elsewhere in this issue.

\section{Clinical Syndromes and Deficits}

\section{Overview}

The classic clinical picture of PSP features severe gait and balance impairment, generalized bradykinesia resembling that of PD, frontal dementia, visual impairment from gaze palsy, spastic/ataxic dysarthria, and dysphagia leading to aspiration. Less specific or inconstant features include depression, sleep disturbance, urinary incontinence, constipation, apraxia, tremor, dystonia, and retrocollis. Atypical clinical phenotypes of autopsy-typical cases have been recognized since the early 1980s, but these were not systematized or validated as statistically separable syndromes until 2005. In that year, Williams et al found that 54\% of their 103 autopsy-typical cases conformed to the classic PSP syndrome and $32 \%$ comprised a group with more asymmetry, tremor, and levodopa response and less dementia that they named "PSP-parkinsonism." The remainder had a combined or indeterminate picture. Since that time, others found gait freezing as the clinical presentation in $3 \%$ and corticobasal syndrome or apraxia of speech each in $\sim 1 \%$.

The imperfect correlation of the classic pathology of PSP to its classic clinical picture has prompted the recent adoption of the term "PSP syndrome" for the latter.

\section{Cognitive and Behavioral Changes}

The cognitive loss of PSP is predominantly frontal, at least early in the course, causing some to consider PSP a category of frontotemporal dementia. At movement disorder centers, the cognitive or behavioral changes are the presenting feature of PSP in over $30 \%$ of cases. ${ }^{5}$ Eventually over $80 \%$ of patients are affected and the deficit can progress quickly. ${ }^{40}$ The consistent issues are apathy, intellectual slowing, and impairment of "executive" functions. These are partly related to slowed central sensory processing, which is markedly abnormal in PSP, 50\% longer than in PD. ${ }^{41,42}$

Long delays in response up to several minutes, along with depression and apathy, can create a false impression of a global dementia. Prominent frontal deficits with little agitation, irritability, aphasia, or abnormal motor behaviors such as wandering help distinguish the dementia of PSP from that of Alzheimer disease. ${ }^{43}$

Prominent frontal cognitive defects in PSP are poor performance of seeing patterns, initiating action, sorting, problem-solving, and abstract thinking. ${ }^{44,45}$ Two examination tasks easy to perform in a clinical setting are (1) lexical fluency, where the patient has one minute to name as many items as possible from a given category such as words starting with " $m$ " or things found in a supermarket; and (2) set-shifting trailmaking, where the patient must use a pen to trace from A to 1 to $B$ to 2 , etc. ${ }^{46}$ Convenient office tests of frontal disinhibition include having the patient perform task A (e.g., tapping once) when the examiner performs task B (e.g., tapping twice) and vice versa, the ability to direct gaze toward the examiner's hand that does not wave (the "antisaccade task"), and the ability to exactly imitate the examiner who claps three times (the "applause sign"). ${ }^{44,45}$

Spontaneous frontal motor behaviors can be dramatic in PSP. ${ }^{45-47}$ Most obvious are forced grasping with the hand or gaze, imitative behavior such as spontaneously mimicking the examiner's hand movements, and motor perseveration as in the applause sign. It is striking how the examiner, after stopping a patient from clapping after 20 or more claps, asks, "Did you do that correctly?" and is answered insightfully, "No, I wanted to stop after only three." Palilalia is also common in PSP and can be disabling. ${ }^{46}$ These signs in the presence of parkinsonism should arouse suspicion of PSP, but the combination can also occur in PD and MSA of the parkinsonian type. ${ }^{48}$

Apraxia is a cognitive problem in $36 \%$ of patients with PSP in one cross-sectional survey. ${ }^{40}$ It is usually asymmetric, as in corticobasal degeneration, and emphasizes sequence errors rather than awkwardness or spatial errors. ${ }^{49}$ It can also take the form of unilateral arm levitation. ${ }^{50}$ Such cases underline the clinical and pathologic overlap between PSP and corticobasal degeneration.

Behavioral abnormalities, particularly apathy and depression, are common on PSP. Apathy is defined as indifference, even to one's illness. Depression is an alteration in mood that can produce apathy. The PSP literature often fails to distinguish between the two or to use a set of controls with Alzheimer disease. The sole study to date that avoided both drawbacks evaluated 22 consecutive patients with PSP and 50 with AD using a formal neuropsychiatric scale. ${ }^{43}$ Apathy was present in $91 \%$, a figure far higher than in $\mathrm{AD}$. Lower frequencies occurred for depression, anxiety, and agitation, and none had hallucinations or delusions. For all of the latter phenomena, the percentages were higher for AD than for PSP.

Depression is present in more than half of patients with PSP using cross-sectional sampling. Agitation, irritability, and disinhibition are each present in about a third of patients. ${ }^{51}$

The apathy of PSP is especially evident in visual cognitive tasks. An altitudinal visual attentional deficit arising from damaged tectal centers may contribute to overloading the fork, poor aim of the urinary stream, and poor attention to dress out of proportion to dementia. ${ }^{52}$ Patients with PSP seem less aware of their postural instability than patients with the same degree of instability of other causes. This contributes to fall risk and to early 
confinement to wheelchair. Unfortunately, apathy for their disability together with frontal impulsivity may conspire to produce the dangerous "rocket sign," suddenly arising from the wheelchair and attempting to walk. After the event, the more articulate patients report that they were aware of their gait difficulty at one level, but did not care at another level, and in any case were unable to inhibit the attempt.

\section{Supranuclear Eye Movement}

Impairment of gaze, the deficit for which PSP was named, may not appear until late in the course, if at all. ${ }^{53,54}$ Symptomatic eye movement difficulty begins a median of 3.9 years after disease onset, over half the overall clinical course. ${ }^{14}$ Before that time, however, most patients exhibit slowing of vertical saccades, "apraxia" of gaze initiation, saccadic pursuit, breakdown of opticokinetic nystagmus in the vertical plane, disordered Bell phenomenon, poor convergence, and square-wave jerks. ${ }^{55,56}$ The last finding has perhaps the greatest sensitivity for PSP, but do occur occasionally in PD, multiple system atrophy, and other cerebellar degenerations. ${ }^{57}$ of great specificity for PSP is a delay in saccade initiation, at times so prolonged as to give the appearance of the patient's not having heard or attended to the examiner's command. Such delays may constitute visual prehension, also called perseveration of gaze, a result of frontal lobe damage. ${ }^{58}$

Later in the course, the patient loses range of vertical gaze, with downgaze usually (but far from always) worse than upgaze. Voluntary gaze without a specific target (i.e., "look down") is usually worse than command gaze to a target, which is worse than pursuit, and reflex gaze is by far the least affected. Slowing of downward saccades, listed above as one of the earliest signs of PSP, can become quite severe (the "marble in oil" phenomenon) even without restriction of range of gaze. Oculocephalic reflexes are preserved throughout disease progression and worsening eye movement abnormalities.

Eyelid movement problems in the form of reduced blink frequency or blepharospasm are common in PSP. ${ }^{59}$ The former, with frequencies typically $5 / \mathrm{min}$ (compared with $10-15 / \mathrm{min}$ for PD and $20-25 / \mathrm{min}$ for controls), ${ }^{59}$ can produce drying with exposure conjunctivitis and reactive lacrimation. Blepharospasm, occurring in about a third of patients, can produce functional blindness. Fortunately, it responds well to injection of botulinum toxin into the lid muscles. It has been called "apraxia of eyelid opening," but is not a true apraxia, as the motor pathway controlling lid movement is impaired.

\section{Motor Parkinsonism}

Postural instability is the initial symptom in approximately twothirds of patients with Richardson syndrome. ${ }^{60,61}$ For patients with PSP-parkinsonism, falls start much later but eventually occur in $81 \%{ }^{5}$ The falls are often unexplained, prompting the term "paroxysmal dysequilibrium." Patients at this point are typically investigated for vestibulopathy, syncope, epilepsy, myelopathy, or posterior fossa ischemia. In PD gait difficulty or postural instability is a presenting feature in only $11 \%{ }^{7}$

Gait "freezing," also called apraxia of gait, is occasionally the initial or only gait abnormality. ${ }^{62}$ In such cases, there may be no rigidity and this phenomenon has received designation as a PSP variant called "PSP-pure akinesia with gait freezing." It accounts for $3 \%$ of autopsy-proven cases. ${ }^{63}$

Tremor at rest, contrary to widespread impression, is not rare in PSP, occurring in $\sim 5$ to $10 \%$ of patients, usually early in the course. ${ }^{5}$ Action or postural tremor occurs in $\sim 25 \%$ overall, in $10 \%$ of patients with Richardson syndrome and $39 \%$ of those with PSP-parkinsonism. ${ }^{5}$

Limb rigidity and distal bradykinesia are mild relative to axial rigidity and bradykinesia. The rigidity tends to increase from wrist to elbow to shoulder, and is far greater in the neck than in the trunk. ${ }^{64}$ In performing tests of distal rapid alternating movements such as finger taps, patients with PSP typically will maintain an impaired amplitude of movement, while in PD, the amplitude steadily decreases. ${ }^{65}$ Similarly, although micrographia is even more common in PSP than in $\mathrm{PD}$, the size of the writing does not decrease along the line as it does in PD. ${ }^{65}$

Retrocollis, which many neurologists consider a hallmark of PSP, is a specific, but not sensitive sign of PSP, occurring in only $\sim 10 \%$. A neck posture that is unexpectedly erect for a parkinsonian disorder is far more common but often unnoticed by an inexperienced examiner.

\section{Sleep and Arousal}

Both primary insomnia (difficulty falling asleep) and secondary insomnia (difficulty remaining asleep or returning to sleep after voids, for example) are frequent complaints in PSP. Overall sleep efficiency is poor at $43 \%,{ }^{66}$ which compares with $63 \%$ for PD. Rapid eye movement (REM) behavioral disorder (RBD) is less frequent than in PD, occurring in 35\% of patients with PSP and $95 \%$ of those with PD, ${ }^{66}$ contrary to the assertion that REM behavioral disorder is a sign of synucleinopathy. The most important specific abnormality on polysomnography is a severe reduction in REM sleep. ${ }^{65,67}$ During what REM sleep remains, there are abnormal slow waves and absence of normal sawtooth waves. ${ }^{68}$ The sensitivity and specificity of these abnormalities has prompted a recommendation that polysomnography be performed routinely for all patients with diagnostically equivocal PSP. ${ }^{69}$

A nonspecific problem, sleep-disordered breathing, occurred in 55\% of patients with PSP in one series. ${ }^{66}$ Another nonspecific issue, restless legs syndrome, was found in only one of 27 patients with PSP (4\%), similar to controls, compared with $10 \%$ for PD.

The profound sleep disorder is presumably related to damage to the (serotonergic) raphe nuclei, the (cholinergic) pedunculopontine nucleus and others, the (noradrenergic) locus ceruleus, and the periaqueductal gray. ${ }^{1}$

Daytime hypersomnolence is a disabling problem in PSP, with fragmentation of sleep-wake periods that culminate in a constant, stuporous state from which the patient can be only briefly roused. It is presumably related to damage to the dopaminergic systems that maintain wakefulness.

The brainstem centers mediating auditory startle and auditory blink reflexes, the nucleus reticularis pontis caudalis in the pontine reticular formation, degenerate in PSP, resulting in loss or major impairment of those responses. ${ }^{70}$ The response is nearly normal in PD. 


\section{Dysarthria}

Within 2 years after disease onset, $41 \%$ of patients with PSP or their families have detected dysarthria. ${ }^{14}$ It eventually develops in 90\% in Richardson syndrome and 81\% in PSP-parkinsonism. ${ }^{5}$ It is a variable combination of, in descending order of importance, spasticity, hypophonia, and ataxia. ${ }^{71,72}$ The combination of a slow rate of speech with a strained and strangled quality and sometimes a hyperkinetic, ataxic component is highly specific for PSP.

\section{Dysphagia}

Aspiration pneumonia is a major risk in advanced PSP and its principal proximate cause of death. But like virtually all other features of PSP, the onset of dysphagia can be delayed. The median latency to onset of dysphagia was 48 months in one study $^{14}$ and 42 months in another. ${ }^{73}$ Only $18 \%$ of patients report symptomatic dysphagia within 2 years after PSP onset, and $46 \%$ do so by 5 years. ${ }^{14}$

Relative to the morbidity it causes, the dysphagia of PSP has received little research attention. Videofluoroscopy in PSP patients ${ }^{74-76}$ with symptomatic dysphagia and a series examined with fiberoptic endoscopy ${ }^{77}$ show parkinsonian rigidity of the oral and pharyngeal muscles as a contributing factor in 80\%, and an assortment of abnormalities emphasizing lingual movement difficulty in all. Esophageal problems occurred in fewer than half, and nasal reflux in none. Coughing on contrast material occurred in a quarter of these early patients, but aspiration was rare. There was frequent premature leakage of chewed food from mouth to pharynx and marked pooling in the valleculae and piriform sinuses.

The dysphagia of PSP, while arising from many levels of the oropharyngeal axis, emphasizes oral rather than pharyngeal abnormalities, distinguishing it from the dysphagia of PD. ${ }^{75}$

Patients with PSP often overload the fork or are uninhibited in stuffing the mouth. The cause may be a combination of poor downgaze, frontal disinhibition, and vertical visual inattention. ${ }^{52}$ The retrocollis in a few patients may disrupt proper alignment of pharynx with esophagus, favoring passage into the airway.

\section{Urinary Incontinence}

A large majority of patients with PSP develop urinary bladder difficulties, starting with urgency and progressing quickly to incontinence. In one series, urinary incontinence occurred in $42 \%$ of patients, beginning a mean of 3.5 years into the disease course. $^{78}$ In fact, these abnormalities are as frequent and severe as in multiple system atrophy, and include incomplete emptying and detrusor hyperreflexia, although detrusor dyssynergia is unusual. ${ }^{79}$ However, there is little or no generalized autonomic dysfunction in $\mathrm{PSP}^{80}$ a point useful in its clinical differentiation from MSA or PD.

\section{Diagnostic Criteria}

Multiple sets of diagnostic criteria have been proposed for PSP. The one with positive predictive value and specificity approaching $100 \%$ is that of Litvan et al, ${ }^{7,81}$ called the National Institute of Neurological Disorders and Stroke-Society for
Progressive Supranuclear Palsy (NINDS-SPSP) Criteria after the organizations funding the autopsy-based project. The criteria offer a set for "possible PSP," emphasizing sensitivity at the expense of specificity, and a set of "probable PSP," emphasizing specificity and positive predictive value but sacrificing sensitivity (83\%). (-Table 1) "Definite PSP" requires autopsy confirmation. Pathoanatomic diagnostic criteria are also available and have reached wide acceptance. ${ }^{82}$

The NINDS-SPSP criteria were formulated before the formal description of clinical phenotypes other than Richardson syndrome. An effort is now under way to redress this shortcoming (Günter U. Höglinger, MD, personal communication).

\section{Progression and Natural History}

The mean onset age of PSP is 63 years, whereas in PD the age is typically 59 years. The standard deviation for PSP is only 6.4 years, suggesting a smaller range of etiologic factors than in $\mathrm{PD}$, where the standard deviation is 12.0 years.

Survival from the time of symptom onset in PSP ranges from 5.3 to 9.7 years, with a typical figure of 7.4 years. ${ }^{8}$ In the United States, the subsequent survival of those reaching age 63 is 23.5 years. The most important known predictor of progression is the Richardson syndrome (RS) phenotype, with a survival of 5.9 years, compared with 9.1 years for PSP-parkinsonism (PSP-P) in the same study. ${ }^{5}$ Acquisition of disability milestones is similarly slower in PSP-P than in RS. ${ }^{83}$ Male gender and older onset age have much less important (but statistically significant) unfavorable effects on PSP progressivity. ${ }^{82,84}$ The severity of the cognitive impairment and the early appearance of dysphagia are also important predictors of rapid progression. ${ }^{84}$

The order of appearance of cardinal deficits is highly variable. Gait difficulty is the presenting motor symptom in $\sim 60 \%$ of cases. Tremor, dysarthria, or vague visual symptoms are part of the presenting picture in $\sim 10 \%$ of cases. ${ }^{61}$ Cognitive and behavioral features are among the earliest appearing features, but the degree to which this is true varies greatly by whether the series is based at a movement disorders center or a dementia center, and on diagnostic criteria used.

The Progressive Supranuclear Palsy Rating Scale ${ }^{8}$ has proven useful as a reproducible measure of disability in PSP that is sensitive to disease progression. ${ }^{85,86}$ It is designed for routine clinical use, requiring $\sim 10$ minutes to administer. It has reached wide acceptance among industry, academic, and regulatory communities as the best available outcome measure for clinical trials in PSP at present. The score ranges from 0 (normal) to 100 and progresses, on average, 10 to 11 points per year over the entire range relevant to clinical trials. It is not copyrighted and is available at www.psp.org/education/ professionals.html. Potential weaknesses of the PSPRS are the need for neurologic examination skills and incomplete interrater reliability testing to date. ${ }^{86}$

\section{Treatment}

Despite several recent multicenter trials of hopeful neuroprotectives, treatment of PSP remains symptomatic. 
Table 1 National Institute of Neurological Disorders and Stroke -Society for Progressive Supranuclear Palsy criteria for the diagnosis of progressive supranuclear palsy (PSP; proposed by Litvan et al)

\begin{tabular}{|c|}
\hline “Possible" PSP \\
\hline All 3 of these: \\
\hline Gradually progressive bradykinetic disorder \\
\hline Onset at age 40 or later \\
\hline $\begin{array}{l}\text { No evidence for competing diagnostic possibilities. } \\
\text { Plus either of these: }\end{array}$ \\
\hline Vertical gaze palsy \\
\hline Or \\
\hline $\begin{array}{l}\text { Slowing of vertical saccades and prominent } \\
\text { postural instability with falls in the first year }\end{array}$ \\
\hline "Probable" PSP \\
\hline All 5 of these: \\
\hline Gradually progressive bradykinetic disorder \\
\hline Onset at age 40 or later \\
\hline No evidence for competing diagnostic possibilities \\
\hline Vertical gaze palsy \\
\hline $\begin{array}{l}\text { Slowing of vertical saccades and prominent } \\
\text { postural instability with falls in the first year }\end{array}$ \\
\hline Criteria that would exclude PSP from consideration: \\
\hline Recent encephalitis \\
\hline $\begin{array}{l}\text { Alien limb syndrome, cortical sensory defects } \\
\text { or temporoparietal atrophy }\end{array}$ \\
\hline Psychosis unrelated to dopaminergic treatment \\
\hline Important cerebellar signs \\
\hline Important unexplained dysautonomia \\
\hline Severe, asymmetric parkinsonian signs \\
\hline $\begin{array}{l}\text { Relevant structural abnormality of basal ganglia on } \\
\text { neuroimaging }\end{array}$ \\
\hline $\begin{array}{l}\text { Whipple's disease on cerebrospinal fluid polymerase } \\
\text { chain reaction, if indicated }\end{array}$ \\
\hline
\end{tabular}

\section{Drug Treatment}

Levodopa may help the rigidity and bradykinesia of PSP. There are no controlled trials, but in a review of 82 patients' drug responses, we found carbidopa/levodopa to have benefited $31 \%$ mildly and $7 \%$ moderately. ${ }^{87}$ This may be no higher than the $30 \%$ placebo response rate typically seen in treatment trials of PD. Adverse effects were uncommon, reported as mild in $17 \%$ and moderate in $6 \%$ despite dosages that typically far exceeded those given in PD. A review of 102 autopsyconfirmed patients' drug responses showed a similar response rate of $32 \%{ }^{5}$ The $50 \%$ response rate in PSP-parkinsonism far exceeds the $14 \%$ in Richardson syndrome. ${ }^{5}$ Most specialists titrate the levodopa dosage (with carbidopa) to at least $1,200 \mathrm{mg}$ per day before concluding that it is ineffective, as a few patients respond only to a high dosage. Fortunately, levodopa dyskinesias are rare in PSP. ${ }^{87}$ Even if a response occurs initially, it may decline and disappear over the following months. For that reason, the need for the drug should be re-evaluated frequently. Unfortunately, the apomorphine test has a high false-positive rate in predicting a levodopa response, ${ }^{88}$ and treatment with dopamine agonists has no more success than levodopa with a higher rate of adverse effects. $^{89}$

The mitochondrial nutrient coenzyme Q-10 gave modest benefit in one 21-patient double-blind study ${ }^{90}$ with no important adverse effects. The subjects, after 6 weeks' treatment, scored 1.6 points better than placebo controls on the PSP Rating Scale, ${ }^{14}$ equivalent to $4 \%$ of the mean baseline score. Improvement in the Frontal Assessment Battery and in magnetic resonance spectroscopic measures of striatal energy metabolism was similarly observed. The dosage of $5 \mathrm{mg} /$ $\mathrm{kg} / \mathrm{d}$ was given as a liquid "nano-dispersion" that is claimed to enter mitochondria more readily than the generally available form. This dosage would cost, at the time of this writing, approximately $\$ 100$ per month and as a nonprescription item, is not covered by insurance companies in the United States. Therefore, any attempt to treat a patient with coenzyme Q-10 should include careful quantitative baseline and on-treatment evaluations for efficacy.

Amantadine was found in our clinic's retrospective study to have provided mild-to-moderate benefit for at least a few months in $40 \%$ of patients with PSP, but with adverse effects, usually moderate in a majority (87 and unpublished observations). The benefit is typically in gait, dysphagia, and apathy, and is compatible with a nonspecific activating effect. The adverse effects are typically anticholinergic with dry mouth, constipation, and confusion. It is therefore justifiable to start nondemented patients with PSP on $100 \mathrm{mg}$ per day and titrate to no more than $100 \mathrm{mg}$ twice daily. If a benefit is not reported by the patient or family after a month, it should be discontinued. When an amantadine regimen in place for more than a few months is abruptly discontinued, there may be a withdrawal effect consisting of exacerbation of PSP symptoms. A longstanding amantadine regimen should therefore be tapered over a period of at least a month.

Amitriptyline gave benefit in a four-patient double-blind $\operatorname{trial}^{91}$ and in our retrospective study ${ }^{87}$ did slightly less well than amantadine. However, it can cause dangerous paradoxical gait difficulties in PSP, and our clinic no longer uses it for that condition.

Many other drugs have been tested to varying degrees of formality in PSP. Any reported benefits have been either refuted by subsequent studies or exceeded by adverse effects. Those that have received large, double-blind trials are the potential neuroprotectants riluzole, ${ }^{92}$ lithium (Galpern et al, unpublished), davunetide (Boxer et al, unpublished), and tideglusib. ${ }^{93}$

Botulinum toxin has proven useful in PSP for blepharospasm and for its variant, so-called apraxia of lid opening. ${ }^{94,95}$ Anticholinergic drugs may assist in this effect according to an anecdotal report, ${ }^{95}$ as may "lid crutches" attached to eyeglasses by an optician. Torticollis or retrocollis in PSP, which can be painful and may prevent proper hygiene, may also respond. However, injections in the anterior or 
lateral neck may secondarily affect the swallowing muscles and induce aspiration in the setting of PSP with poorly compensated dysphagia.

Management of depression, psychosis, agitation, insomnia, constipation, and urinary urgency or incontinence in PSP requires nonspecific palliative measures used in any patients with a chronic dementing, motor disorder. As for any parkinsonian disorder, dopamine-blocking neuroleptics should be avoided, although quetiapine and clozapine are probably better tolerated. Deserving specific mention are the anticholinesterase drugs for cognitive disturbance. Donepezil has performed poorly in PSP, ${ }^{96,97}$ but results with rivastigmine justify an attempt. ${ }^{98}$

\section{Nondrug Treatment}

Common sense antifalling measures should be undertaken early in the course of PSP. These include installing grab bars, especially in bathrooms, where walkers are difficult to use, and removing low-lying obstacles such as coffee tables, loose rugs, and grandchildren's toys. The difficulty in directing gaze down to the dinner plate can often be overcome by holding the fork at eye level and "pulling" gaze downward or by elevating the plate on a platform. Physical therapy should be attempted, although evidence of its efficacy for gait and balance is only anecdotal. ${ }^{99-101}$ Evidence for efficacy of gaze retraining is somewhat more convincing, however. ${ }^{102}$ Although prisms are not effective for the vertical gaze palsy, they can be helpful for the symptom of diplopia. Methylcellulose or polyvinyl alcohol drops often help the chronic conjunctivitis and its reactive lacrimation and its low blink rate. At bedtime, this may be supplemented by petrolatumbased ointment, which has a longer duration of action but must be wiped away before attempting a nocturnal bathroom trip.

Dysphagia management is critical in PSP. A formal swallowing evaluation with a modified barium swallow (MBS; not a routine barium esophagram) should be ordered at the first evidence of slowed or fragmented swallowing. This videoradiographic procedure assesses all phases of consuming a range of textures from water to a dry cracker. The physician should explain and enforce any dietary or feeding modification recommendations arising from the evaluation. The evaluation should be repeated once the patient's ability to compensate using the previous set of measures has waned.

The issue of a feeding tube, typically via percutaneous endoscopically-placed gastrostomy (PEG), will be a question at some point for many patients. This requires a careful, individualized, family-based assessment taking into account the patient's ability to live a meaningful life, given the other serious neurologic deficits of PSP. In most referral clinics, PEG feeding is recommended only for those few patients whose dysphagia has progressed far faster than the dementia. The decision is made more difficult by the likelihood that improving nutrition and hydration via the PEG can improve overall neurologic function. Patients and their families must be cautioned that the PEG will not eliminate the risk of aspiration, the most common cause of mortality in PSP.

\section{References}

1 Steele JC, Richardson JC, Olszewski J. Progressive supranuclear palsy: a heterogeneous degeneration involving the brain stem, basal ganglia and cerebellum, with vertical gaze and pseudobulbar palsy, nuchal dystonia and dementia. Arch Neurol 1964; 10:333-359

2 Pollock NJ, Mirra SS, Binder LI, Hansen LA, Wood JG. Filamentous aggregates in Pick's disease, progressive supranuclear palsy, and Alzheimer's disease share antigenic determinants with microtubule-associated protein, tau. Lancet 1986;2(8517):1211

3 Baker M, Litvan I, Houlden $\mathrm{H}$, et al. Association of an extended haplotype in the tau gene with progressive supranuclear palsy. Hum Mol Genet 1999;8(4):711-715

4 Albers DS, Augood SJ, Park LC, et al. Frontal lobe dysfunction in progressive supranuclear palsy: evidence for oxidative stress and mitochondrial impairment. J Neurochem 2000;74(2):878-881

5 Williams DR, de Silva R, Paviour DC, et al. Characteristics of two distinct clinical phenotypes in pathologically proven progressive supranuclear palsy: Richardson's syndrome and PSP-parkinsonism. Brain 2005;128(Pt 6):1247-1258

6 Lewis J, McGowan E, Rockwood J, et al. Neurofibrillary tangles, amyotrophy and progressive motor disturbance in mice expressing mutant (P301L) tau protein. Nat Genet 2000;25(4):402-405

7 Litvan I, Agid Y, Calne D, et al. Clinical research criteria for the diagnosis of progressive supranuclear palsy (Steele-RichardsonOlszewski syndrome): report of the NINDS-SPSP international workshop. Neurology 1996;47(1):1-9

8 Golbe LI, Ohman-Strickland PA. A clinical rating scale for progressive supranuclear palsy. Brain 2007;130(Pt 6):1552-1565

9 Baron JC, Maziere B, Loc'h C, Sgouropoulos P, Bonnet AM, Agid Y. Progressive supranuclear palsy: loss of striatal dopamine receptors demonstrated in vivo by positron tomography. Lancet 1985 ; 1(8438):1163-1164

10 Nath U, Ben-Shlomo Y, Thomson RG, et al. The prevalence of progressive supranuclear palsy (Steele-Richardson-Olszewski syndrome) in the UK. Brain 2001;124(Pt 7):1438-1449

11 Schrag A, Ben-Shlomo Y, Quinn NP. Prevalence of progressive supranuclear palsy and multiple system atrophy: a cross-sectional study. Lancet 1999;354(9192):1771-1775

12 Bower JH, Maraganore DM, McDonnell SK, Rocca WA. Incidence of progressive supranuclear palsy and multiple system atrophy in Olmsted County, Minnesota, 1976 to 1990. Neurology 1997; 49(5):1284-1288

13 Kawashima M, Miyake M, Kusumi M, Adachi Y, Nakashima K. Prevalence of progressive supranuclear palsy in Yonago, Japan. Mov Disord 2004;19(10):1239-1240

14 Davis PH, Golbe LI, Duvoisin RC, Schoenberg BS. Risk factors for progressive supranuclear palsy. Neurology 1988;38(10): 1546-1552

15 Golbe LI, Rubin RS, Cody RP, et al. Follow-up study of risk factors in progressive supranuclear palsy. Neurology 1996;47(1):148-154

16 Vidal JS, Vidailhet M, Derkinderen P, de Gaillarbois TD, Tzourio C, Alpérovitch A. Risk factors for progressive supranuclear palsy: a case-control study in France. J Neurol Neurosurg Psychiatry 2009; 80(11):1271-1274

17 Odetti P, Garibaldi S, Norese R, et al. Lipoperoxidation is selectively involved in progressive supranuclear palsy. J Neuropathol Exp Neurol 2000;59(5):393-397

18 Golbe LI, Davis PH, Schoenberg BS, Duvoisin RC. Prevalence and natural history of progressive supranuclear palsy. Neurology 1988;38(7):1031-1034

19 Ghika J, Bogousslavsky J. Presymptomatic hypertension is a major feature in the diagnosis of progressive supranuclear palsy. Arch Neurol 1997;54(9):1104-1108

20 Höglinger GU, Melhem NM, Dickson DW, et al. Common variants affect risk for the tauopathy progressive supranuclear palsy. Nat Genet 2011;43:699-705 
21 Ruberg M, Javoy-Agid F, Hirsch E, et al. Dopaminergic and cholinergic lesions in progressive supranuclear palsy. Ann Neurol 1985;18(5):523-529

22 Hauw J-J, Verny M, Delaère P, Cervera P, He Y, Duyckaerts C. Constant neurofibrillary changes in the neocortex in progressive supranuclear palsy. Basic differences with Alzheimer's disease and aging. Neurosci Lett 1990;119(2):182-186

23 Levy R, Ruberg M, Herrero MT, et al. Alterations of GABAergic neurons in the basal ganglia of patients with progressive supranuclear palsy: an in situ hybridization study of GAD67 messenger RNA. Neurology 1995;45(1):127-134

24 Pascual J, Berciano J, González AM, Grijalba B, Figols J, Pazos A. Autoradiographic demonstration of loss of alpha 2-adrenoceptors in progressive supranuclear palsy: preliminary report. J Neurol Sci 1993;114(2):165-169

25 Benarroch EE. Pedunculopontine nucleus: functional organization and clinical implications. Neurology 2013;80(12):1148-1155

26 Padovani A, Borroni B, Brambati SM, et al. Diffusion tensor imaging and voxel based morphometry study in early progressive supranuclear palsy. J Neurol Neurosurg Psychiatry 2006;77(4): 457-463

27 Sawa N, Kataoka H, Kiriyama T, et al. Cerebellar dentate nucleus in progressive supranuclear palsy. Clin Neurol Neurosurg 2014; 118:32-36

28 Zwergal A, la Fougère C, Lorenzl S, et al. Postural imbalance and falls in PSP correlate with functional pathology of the thalamus. Neurology 2011;77(2):101-109

29 Liscic RM, Srulijes K, Gröger A, Maetzler W, Berg D. Differentiation of progressive supranuclear palsy: clinical, imaging and laboratory tools. Acta Neurol Scand 2013;127(5):362-370

30 Tripathi M, Dhawan V, Peng S, et al. Differential diagnosis of parkinsonian syndromes using F-18 fluorodeoxyglucose positron emission tomography. Neuroradiology 2013;55(4):483-492

31 Ilgin N, Zubieta J, Reich SG, Dannals RF, Ravert HT, Frost JJ. PET imaging of the dopamine transporter in progressive supranuclear palsy and Parkinson's disease. Neurology 1999;52(6):1221-1226

32 Blin J, Baron JC, Dubois B, et al. Positron emission tomography study in progressive supranuclear palsy. Brain hypometabolic pattern and clinicometabolic correlations. Arch Neurol 1990; 47(7):747-752

33 Rollin-Sillaire A, Bombois S, Deramecourt V, et al. Contribution of single photon emission computed tomography to the differential diagnosis of dementia in a memory clinic. J Alzheimers Dis 2012; 30(4):833-845

34 Van Laere K, Casteels C, De Ceuninck L, et al. Dual-tracer dopamine transporter and perfusion SPECT in differential diagnosis of parkinsonism using template-based discriminant analysis. J Nucl Med 2006;47(3):384-392

35 Guevara CA, Blain CR, Stahl D, Lythgoe DJ, Leigh PN, Barker GJ. Quantitative magnetic resonance spectroscopic imaging in Parkinson's disease, progressive supranuclear palsy and multiple system atrophy. Eur J Neurol 2010;17(9):1193-1202

36 Albrecht P, Müller AK, Südmeyer M, et al. Optical coherence tomography in parkinsonian syndromes. PLoS ONE 2012;7(4): e34891

37 Serrao M, Di Fabio R, Bartolo M, et al. The contribution of trigemino-cervical reflexes in distinguishing progressive supranuclear palsy from multiple system atrophy. Clin Neurophysiol 2011;122(9):1812-1815

38 Hall S, Öhrfelt A, Constantinescu R, et al. Accuracy of a panel of 5 cerebrospinal fluid biomarkers in the differential diagnosis of patients with dementia and/or parkinsonian disorders. Arch Neurol 2012;69(11):1445-1452

39 Winikates J, Jankovic J. Vascular progressive supranuclear palsy. J Neural Transm Suppl 1994;42:189-201

40 Soliveri P, Piacentini S, Girotti F. Limb apraxia in corticobasal degeneration and progressive supranuclear palsy. Neurology 2005;64(3):448-453
41 Johnson R Jr, Litvan I, Grafman J. Progressive supranuclear palsy: altered sensory processing leads to degraded cognition. Neurology 1991;41(8):1257-1262

42 Dubois B, Pillon B, Legault F, Agid Y, Lhermitte F. Slowing of cognitive processing in progressive supranuclear palsy. A comparison with Parkinson's disease. Arch Neurol 1988;45(11): 1194-1199

43 Litvan I, Mega MS, Cummings JL, Fairbanks L. Neuropsychiatric aspects of progressive supranuclear palsy. Neurology 1996;47(5): 1184-1189

44 Pillon B, Gouider-Khouja N, Deweer B, et al. Neuropsychological pattern of striatonigral degeneration: comparison with Parkinson's disease and progressive supranuclear palsy. J Neurol Neurosurg Psychiatry 1995;58(2):174-179

45 Grafman J, Litvan I, Gomez C, Chase TN. Frontal lobe function in progressive supranuclear palsy. Arch Neurol 1990;47(5): 553-558

46 Podoll K, Schwarz M, Noth J. Language functions in progressive supranuclear palsy. Brain 1991;114(Pt 3):1457-1472

47 Cambier J, Masson M, Viader F, Limodin J, Strube A. [Frontal syndrome of progressive supranuclear palsy]. Rev Neurol (Paris) 1985;141(8-9):528-536

48 Robbins TW, James M, Owen AM, et al. Cognitive deficits in progressive supranuclear palsy, Parkinson's disease, and multiple system atrophy in tests sensitive to frontal lobe dysfunction. J Neurol Neurosurg Psychiatry 1994;57(1):79-88

49 Leiguarda RC, Pramstaller PP, Merello M, Starkstein S, Lees AJ, Marsden CD. Apraxia in Parkinson's disease, progressive supranuclear palsy, multiple system atrophy and neuroleptic-induced parkinsonism. Brain 1997;120(Pt 1):75-90

50 Barclay CL, Bergeron C, Lang AE. Arm levitation in progressive supranuclear palsy. Neurology 1999;52(4):879-882

51 Gerstenecker A, Duff K, Mast B, Litvan I; ENGENE-PSP Study Group. Behavioral abnormalities in progressive supranuclear palsy. Psychiatry Res 2013;210(3):1205-1210

52 Rafal RD, Posner MI, Friedman JH, Inhoff AW, Bernstein E. Orienting of visual attention in progressive supranuclear palsy. Brain 1988;111(Pt 2):267-280

53 Birdi S, Rajput AH, Fenton M, et al. Progressive supranuclear palsy diagnosis and confounding features: report on 16 autopsied cases. Mov Disord 2002;17(6):1255-1264

54 Dubas F, Gray F, Escourolle R. [Steele-Richardson-Olszewski disease without ophthalmoplegia. 6 clinico-anatomic cases]. Rev Neurol (Paris) 1983;139(6-7):407-416

55 Chu FC, Reingold DB, Cogan DG, Williams AC. The eye movement disorders of progressive supranuclear palsy. Ophthalmology 1979;86(3):422-428

56 Marx S, Respondek G, Stamelou M, et al. Validation of mobile eyetracking as novel and efficient means for differentiating progressive supranuclear palsy from Parkinson's disease. Front Behav Neurosci 2012;6:88

57 Rascol O, Sabatini U, Simonetta-Moreau M, Montastruc JL, Rascol A, Clanet M. Square wave jerks in parkinsonian syndromes. J Neurol Neurosurg Psychiatry 1991;54(7):599-602

58 Pierrot-Deseilligny C, Rivaud S, Pillon B, Fournier E, Agid Y. Lateral visually-guided saccades in progressive supranuclear palsy. Brain 1989;112(Pt 2):471-487

59 Golbe LI, Davis PH, Lepore FE. Eyelid movement abnormalities in progressive supranuclear palsy. Mov Disord 1989;4(4):297-302

60 Maher ER, Lees AJ. The clinical features and natural history of the Steele-Richardson-Olszewski syndrome (progressive supranuclear palsy). Neurology 1986;36(7):1005-1008

61 Nath U, Ben-Shlomo Y, Thomson RG, Lees AJ, Burn DJ. Clinical features and natural history of progressive supranuclear palsy: a clinical cohort study. Neurology 2003;60(6):910-916

62 Matsuo H, Takashima H, Kishikawa M, et al. Pure akinesia: an atypical manifestation of progressive supranuclear palsy. J Neurol Neurosurg Psychiatry 1991;54(5):397-400 
63 Williams DR, Holton JL, Strand K, Revesz T, Lees AJ. Pure akinesia with gait freezing: a third clinical phenotype of progressive supranuclear palsy. Mov Disord 2007;22(15):2235-2241

64 Tanigawa A, Komiyama A, Hasegawa O. Truncal muscle tonus in progressive supranuclear palsy. J Neurol Neurosurg Psychiatry 1998;64(2):190-196

65 Ling H, Massey LA, Lees AJ, Brown P, Day BL. Hypokinesia without decrement distinguishes progressive supranuclear palsy from Parkinson's disease. Brain 2012;135(Pt 4):1141-1153

66 Sixel-Döring F, Schweitzer M, Mollenhauer B, Trenkwalder C. Polysomnographic findings, video-based sleep analysis and sleep perception in progressive supranuclear palsy. Sleep Med 2009; 10(4):407-415

67 Aldrich MS, Foster NL, White RF, Bluemlein L, Prokopowicz G. Sleep abnormalities in progressive supranuclear palsy. Ann Neurol 1989;25(6):577-581

68 Leygonie F, Thomas J, Degos JD, Bouchareine A, Barbizet J. [Sleep disorders in Steele-Richardson disease. Polygraphic study of 3 cases]. Rev Neurol (Paris) 1976;132(2):125-136

69 Agid Y, Javoy-Agid F, Ruberg M, et al. Progressive supranuclear palsy: anatomoclinical and biochemical considerations. Adv Neurol 1987;45:191-206

70 Vidailhet M, Rothwell JC, Thompson PD, Lees AJ, Marsden CD. The auditory startle response in the Steele-Richardson-Olszewski syndrome and Parkinson's disease. Brain 1992;115(Pt 4):1181-1192

71 Skodda S, Visser W, Schlegel U. Acoustical analysis of speech in progressive supranuclear palsy. J Voice 2011;25(6):725-731

72 Kluin KJ, Foster NL, Berent S, Gilman S. Perceptual analysis of speech disorders in progressive supranuclear palsy. Neurology 1993;43(3 Pt 1):563-566

73 Müller J, Wenning GK, Verny M, et al. Progression of dysarthria and dysphagia in postmortem-confirmed parkinsonian disorders. Arch Neurol 2001;58(2):259-264

74 Sonies BC. Swallowing and speech disturbances. In: Litvan I, Agid Y, eds. Progressive Supranuclear Palsy: Clinical and Research Approaches. New York: Oxford University Press; 1992:240-254

75 Johnston BT, Castell JA, Stumacher S, et al. Comparison of swallowing function in Parkinson's disease and progressive supranuclear palsy. Mov Disord 1997;12(3):322-327

76 Leopold NA, Kagel MC. Dysphagia in progressive supranuclear palsy: radiologic features. Dysphagia 1997;12(3):140-143

77 Warnecke T, Oelenberg S, Teismann I, et al. Endoscopic characteristics and levodopa responsiveness of swallowing function in progressive supranuclear palsy. Mov Disord 2010;25(9):1239-1245

78 Testa D, Monza D, Ferrarini M, Soliveri P, Girotti F, Filippini G. Comparison of natural histories of progressive supranuclear palsy and multiple system atrophy. Neurol Sci 2001;22(3):247-251

79 Sakakibara R, Hattori T, Tojo M, Yamanishi T, Yasuda K, Hirayama K. Micturitional disturbance in progressive supranuclear palsy. J Auton Nerv Syst 1993;45(2):101-106

80 Kimber J, Mathias CJ, Lees AJ, et al. Physiological, pharmacological and neurohormonal assessment of autonomic function in progressive supranuclear palsy. Brain 2000;123(Pt 7):1422-1430

81 Litvan I, Agid Y, Jankovic J, et al. Accuracy of clinical criteria for the diagnosis of progressive supranuclear palsy (Steele-RichardsonOlszewski syndrome). Neurology 1996;46(4):922-930

82 Hauw J-J, Daniel SE, Dickson D, et al. Preliminary NINDS neuropathologic criteria for Steele-Richardson-Olszewski syndrome (progressive supranuclear palsy). Neurology 1994;44(11):2015-2019

83 O'Sullivan SS, Massey LA, Williams DR, et al. Clinical outcomes of progressive supranuclear palsy and multiple system atrophy. Brain 2008;131(Pt 5):1362-1372
84 dell'Aquila C, Zoccolella S, Cardinali V, et al. Predictors of survival in a series of clinically diagnosed progressive supranuclear palsy patients. Parkinsonism Relat Disord 2013;19(11):980-985

85 Burn DJ. Clinical assessment of progressive supranuclear palsy over time: new rating scale validated. Nat Clin Pract Neurol 2007; 3(11):600-601

86 Hall DA, João Forjaz M, Golbe LI, et al. Scales to assess clinical features of progressive supranuclear palsy. MDS Task Force Report. Mov Disord, In press

87 Nieforth KA, Golbe LI. Retrospective study of drug response in 87 patients with progressive supranuclear palsy. Clin Neuropharmacol 1993;16(4):338-346

88 D'Costa DF, Abbott RJ, Pye IF, Millac PA. The apomorphine test in parkinsonian syndromes. J Neurol Neurosurg Psychiatry 1991; 54(10):870-872

89 Weiner WJ, Minagar A, Shulman LM. Pramipexole in progressive supranuclear palsy. Neurology 1999;52(4):873-874

90 Stamelou M, Reuss A, Pilatus U, et al. Short-term effects of coenzyme Q10 in progressive supranuclear palsy: a randomized, placebo-controlled trial. Mov Disord 2008;23(7):942-949

91 Newman GC. Treatment of progressive supranuclear palsy with tricyclic antidepressants. Neurology 1985;35(8):1189-1193

92 Bensimon G, Ludolph A, Agid Y, Vidailhet M, Payan C, Leigh PN; NNIPPS Study Group. Riluzole treatment, survival and diagnostic criteria in Parkinson plus disorders: the NNIPPS study. Brain 2009;132(Pt 1):156-171

93 Tolosa E, Litvan I, Höglinger GU, et al; TAUROS Investigators. A phase 2 trial of the GSK-3 inhibitor tideglusib in progressive supranuclear palsy. Mov Disord 2014;29(4):470-478

94 Piccione F, Mancini E, Tonin P, Bizzarini M. Botulinum toxin treatment of apraxia of eyelid opening in progressive supranuclear palsy: report of two cases. Arch Phys Med Rehabil 1997;78(5):525-529

95 Krack P, Marion MH. "Apraxia of lid opening," a focal eyelid dystonia: clinical study of 32 patients. Mov Disord 1994;9(6): 610-615

96 Litvan I, Phipps M, Pharr VL, Hallett M, Grafman J, Salazar A. Randomized placebo-controlled trial of donepezil in patients with progressive supranuclear palsy. Neurology 2001;57(3): 467-473

97 Fabbrini G, Barbanti P, Bonifati V, et al. Donepezil in the treatment of progressive supranuclear palsy. Acta Neurol Scand 2001; 103(2):123-125

98 Liepelt I, Gaenslen A, Godau J, et al. Rivastigmine for the treatment of dementia in patients with progressive supranuclear palsy: clinical observations as a basis for power calculations and safety analysis. Alzheimers Dement 2010;6(1):70-74

99 Sosner J, Wall GC, Sznajder J. Progressive supranuclear palsy: clinical presentation and rehabilitation of two patients. Arch Phys Med Rehabil 1993;74(5):537-539

100 Suteerawattananon M, MacNeill B, Protas EJ. Supported treadmill training for gait and balance in a patient with progressive supranuclear palsy. Phys Ther 2002;82(5):485-495

101 Steffen TM, Boeve BF, Petersen CM, Dvorak L, Kantarci K. Longterm exercise training for an individual with mixed corticobasal degeneration and progressive supranuclear palsy features: 10-year case report follow-up. Phys Ther 2014;94(2): 289-296

102 Zampieri C, Di Fabio RP. Improvement of gaze control after balance and eye movement training in patients with progressive supranuclear palsy: a quasi-randomized controlled trial. Arch Phys Med Rehabil 2009;90(2):263-270 